\title{
DINAMIKA LOKAL MODEL EPIDEMI SVIR DENGAN IMIGRASI PADA KOMPARTEMEN VAKSINASI
}

\section{Local Dynamics of an SVIR Epidemic Model with Immigration of Vaccine Compartment}

\author{
Joko Harianto $^{1 *}$, Titik Suparwati ${ }^{2}$, Inda Puspita Sari ${ }^{3}$ \\ ${ }^{1,2}$ Prodi Matematika, Fakultas Matematika dan Ilmu Pengetahuan Alam, Universitas Cenderawasih \\ ${ }^{3}$ Kedokteran Umum, Fakultas Kedokteran, Universitas Cenderawasih \\ Kampus Uncen Baru Waena Jl. Kampwolker, Kota Jayapura, 99351, Indonesia \\ e-mail:1*joharijpr88@gmail.com ; 2tix_az@ymail.com ; ${ }^{3}$ indasarira@yahoo.co.id \\ Corresponding author*
}

\begin{abstract}
Abstrak
Artikel ini termasuk dalam ruang lingkup matematika epidemiologi. Tujuan ditulisnya artikel ini untuk mendeskripsikan dinamika lokal penyebaran suatu penyakit dengan beberapa asumsi yang diberikan. Dalam pembahasan, dianalisis kestabilan titik ekuilibrium model epidemi SVIR dengan adanya imigrasi pada kompartemen vaksinasi. Analisis kestabilan titik ekuilibrium yang dibahas hanya kestabilan lokalnya saja. Dengan langkah pertama, model SVIR diformulasikan, kemudian titik ekuilibriumnya ditentukan, selanjutnya, bilangan reproduksi dasar ditentukan. Pada akhirnya, kestabilan titik ekuilibirum yang bergantung pada bilangan reproduksi dasar ditentukan secara eksplisit. Hasilnya adalah jika bilangan reproduksi dasar kurang dari satu maka terdapat satu titik ekuilbirum dan titik ekuilbrium tersebut stabil asimtotik lokal. Hal ini berarti bahwa dalam kondisi tersebut penyakit akan cenderung menghilang dalam populasi. Sebaliknya, jika bilangan reproduksi dasar lebih dari satu, maka terdapat dua titik ekuilibrium. Dalam kondisi ini, titik ekuilibrium endemik stabil asimtotik lokal dan titik ekuilibrium bebas penyakit tidak stabil. Hal ini berarti bahwa dalam kondisi tersebut penyakit akan tetap ada dalam populasi.
\end{abstract}

Kata Kunci: Model SVIR, Stabil Asimtotik Lokal

\begin{abstract}
This article is included in the scope of mathematical epidemiology. The purpose of this article is to describe the dynamics of the spread of disease with some assumptions given. In this paper, we present an epidemic SVIR model with the presence of immigration in the vaccine compartment. The analysis of equilibrium point stability discussed only local stability. First, we formulate the SVIR model, then the equilibrium point is determined, furthermore, the basic reproduction number is determined. In the end, the stability of the equilibrium point is determined depending on the number of basic reproduction. The result is that if the basic reproduction number is less than one then there is a unique equilibrium point and the equilibrium point is locally asymptotically stable. This means that in those conditions the disease will tend to disappear in the population. Conversely, if the basic reproduction number is more than one, then there are two equilibrium points. The endemic equilibrium point is locally asymptotically stable and the disease-free equilibrium point is unstable. This means that in those conditions the disease will remain in the population.
\end{abstract}

Keywords: SVIR Model, Locally Asymptotically stable. 


\section{PENDAHULUAN}

Dalam beberapa dekade terakhir, pemodelan matematika telah memegang peranan penting dalam teori epidemiologi. Berbagai model epidemi telah diformulasikan dan diselidiki secara luas yang mengarah pada kemajuan besar dalam studi pengendalian dan pencegahan penyakit. Berdasarkan teori epidemiologi [1], penyebaran penyakit menular biasanya dapat dijelaskan secara matematis dengan model kompartemen seperti model SIR atau SIRS. Setiap huruf dari SIR mengacu pada "kompartemen" yang merupakan kondisi seseorang terkait dengan kesehatannya. Oleh sebab itu, vaksinasi juga dapat dipertimbangkan dengan menambahkan beberapa kompartemen secara alami ke dalam model SIR untuk penyakit tertentu. Dalam [2] ditambahkan kompartemen V ke dalam model SIS dan dianalisis pengaruh vaksinasi terhadap penyakit tuberkulosis. Beberapa tahun kemudian, dalam [3] dan [4] dibahas pembentukan model SVIR untuk mempelajari dinamika transmisi influenza dengan vaksinasi. Selanjutnya, dalam [5] diberikan deskripsi beberapa tipe model SVIR yang terkait dengan strategi vaksinasi. Dalam artikel [6] dikembangkan dan dianalisis model SVIR untuk masalah continuous vaccination strategy dan masalah pulse vaccination strategy (PVS). Model SVIR untuk masalah continuous vaccination strategy kemudian dikembangkan dan dibahas dalam beberapa artikel, yaitu dalam [7], [8], [9], [10], [11] dan [12].

Dalam artikel [7] dibahas kestabilan global model SVIR dengan asusmsi populasinya terbuka. Model tersebut melibatkan faktor imigrasi pada semua kompartemen. Kemudian, dalam [9] dibahas model kestabilan lokal dan global model SVIR dengan faktor laju insidensi non-linear dan imigrasi hanya terjadi pada kompartemen vaccinated. Pada tahun yang sama, dalam [8] dibahas kestabilan lokal model SVIR dengan asumsi imigrasi hanya terjadi pada kompartemen infected. Analisis kestabilan model SVIR dalam artikel [6] dibahas kembali dalam [10] dengan menambahkan adanya faktor kematian karena terinfeksi penyakit. Model SVIR yang dibahas dalam artikel [6] diasumsikan memiliki jumlah populasi yang konstan sepanjang waktu. Selanjutnya, untuk kasus populasi yang tidak konstan pada model SVIR dibahas dalam artikel [11]. Artikel tersebut membahas analisis kestabilan lokal model SVIR dan jumlah populasi yang tidak konstan diasumsikan berasal dari laju kematian yang berbeda-beda pada tiap kompartemen. Pembahasan terbaru terkait analisis kestabilan model SVIR dapat dilihat dalam artikel [12]. Artikel tersebut membahas kestabilan lokal model SVIR yang diterapkan pada masalah penyebaran penyakit Difteri di Indonesia. Modelmodel tersebut dibentuk dengan berbagai asumsi yang sesuai dengan kondisi kenyataan di suatu populasi.

Pengkajian model SVIR dengan asumsi adanya imigrasi pada kompartemen Vaccinated perlu dilakukan. Dalam suatu lingkungan tentu saja terjadi proses migrasi. Migrasi dalam kondisi wabah terutama wabah penyakit fatal (penyakit mematikan) tentu saja akan dibatasi. Dengan demikian, ada kemungkinan bahwa yang diijinkan untuk migrasi adalah orang-orang yang telah diberikan vaksin. Penyakit fatal yang dapat diterapkan pada model SVIR dengan asumsi tersebut diantaranya adalah flu burung. Hal tersebut kemudian memotivasi penulis untuk membahas model SVIR dengan asumsi adanya imigrasi pada kompartemen vaksinasi. Dalam artikel ini akan dibahas analisis kestabilan lokal model SVIR dengan asumsi adanya imigrasi yang terjadi pada kompartemen vaccinated dan adanya kematian karena terinfeksi oleh penyakit. Pembahasan ini bertujuan untuk mendeskripsikan analisis kestabilan lokal model SVIR dengan adanya asumsi faktor imigrasi pada kompartemen vaccinated. Artikel ini diharapkan dapat memberikan kontribusi di bidang kesehatan untuk diterapkan dalam membuat simulasi keberlangsungan wabah suatu penyakit.

\section{METODE PENELITIAN}

Pembahasan artikel ini menggunakan metode studi literatur, yaitu mempelajari beberapa artikel ilmiah terkait model SVIR dan analisis kestabilan titik ekuilibriumnya. Berikut ini adalah tahapan pembahasan dalam artikel ini:

1. Membentuk model epidemi SVIR berdasarkan asumsi adanya imigrasi pada kompartemen Vaccinated.

2. Menentukan titik ekuilibrium model SVIR.

3. Menentukan bilangan reproduksi dasar $\left(R_{0}\right)$.

4. Menentukan kestabilan lokal titik ekuilibrium model SVIR yang bergantung pada bilangan reproduksi dasar $\left(R_{0}\right)$. 


\section{HASIL DAN PEMBAHASAN}

\subsection{Formulasi Model}

Populasi dibagi menjadi empat kompartemen, yaitu S (Susceptible), V (Vaccinated), I (Infected) dan $\mathrm{R}$ (Recovery). Total populasi secara keseluruhan dari empat kompartemen tersebut diasumsikan tidak konstan. $S(t)$ menyatakan jumlah populasi yang sehat dan rentan terhadap penyakit pada saat $t, V(t)$ menyatakan jumlah populasi yang telah divaksin pada saat $t, I(t)$ menyatakan jumlah populasi yang terinfeksi penyakit pada saat $t$ dan $R(t)$ menyatakan jumlah individu yang sembuh dari penyakit pada saat $t$. Jika total populasi keseluruhan dari lima kompartemen tersebut pada saat $t$ dinotasikan $N(t)$, maka $N(t)=$ $S(t)+V(t)+I(t)+R(t), \forall t \geq 0$ dengan total populasi awal dinotasikan $N(0)=N_{0}$. Selanjutnya, asumsi-asumsi model dalam pembahasan ini sama dengan pembahasan dalam artikel [6], yaitu semua kelahiran pada setiap kompartemen masuk pada kompartemen rentan, laju kematian setiap kompartemen sama, penyakit dapat sembuh permanen, vaksin diberikan pada kompartemen rentan, seseorang yang telah divaksin dapat tertular jika kondisi imun tubuh turun dan terjadi kontak dengan seseorang yang tertular, kontak dengan sesorang yang terinfeksi merupakan penyebab terjadinya transmisi penyakit. Dua asumsi tambahan dalam pembahasan ini adalah populasi diasumsikan terbuka dan penyakit yang mewabah dapat mematikan. Populasi terbuka yang dimaksud adalah terjadinya imigrasi hanya pada kompartemen $\mathrm{V}$ (Vaccinated) dengan laju konstan. Asumsi yang kedua yaitu adanya kematian individu karena terinfeksi penyakit (penyakit fatal) dan laju kematiannya konstan. Diagram transmisi model SVIR diberikan dalam Gambar 1.

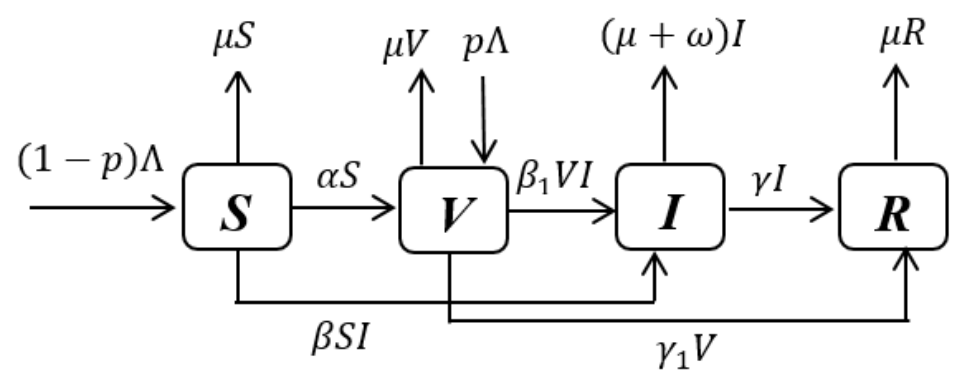

Gambar 1. Diagram transmisi model SVIR

Gambar 1 mengilustrasikan bahwa jumlah individu pada kompartemen $S$ akan bertambah karena adanya kelahiran sebesar $(1-p) \Lambda$. Kemudian jumlah individu pada kompartemen $S$ akan berkurang karena adanya vaksinasi yang diberikan sebesar $\alpha S$, penularan penyakit sebesar $\beta S I$, dan kematian alami sebesar $\mu S$. Jumlah individu pada kompartemen $V$ akan bertambah karena adanya imigrasi sebesar $\mu p$ dan vaksinasi yang diberikan sebesar $\alpha S$. Kemudian jumlah individu pada kompartemen $V$ akan berkurang karena adanya penularan penyakit sebesar $\beta_{1} V I$, individu-individu yang telah memperoleh kekebalan sebesar $\gamma_{1} V$ dan kematian alami sebesar $\mu V$. Jumlah individu pada kompartemen $I$ akan bertambah karena adanya individuindividu yang masuk dari kompartemen rentan sebesar $\beta S I$ dan individu-individu yang masuk dari kompartemen $V$ sebesar $\beta_{1} V I$. Kemudian jumlah individu pada kompartemen $I$ akan berkurang karena adanya kesembuhan individu-individu secara alami sebesar $\gamma I$, kematian alami sebesar $\mu I$ dan kematian karena penyakit sebesar $\omega I$. Jumlah individu pada kompartemen $R$ akan bertambah karena adanya kesembuhan individu-individu secara alami dari kompartemen $I$ sebesar $\gamma I$ dan individu-individu yang memperoleh kekebalan karena telah divaksin sebesar $\gamma_{1} V$. Kemudian jumlah individu pada kompartemen $R$ akan berkurang karena adanya kematian alami sebesar $\mu R$. Secara matematis, model SVIR diformulasikan dalam sistem persamaan diferensial berikut:

$$
\begin{aligned}
& \frac{d S}{d t}=(1-p) \Lambda-\beta S I-(\mu+\alpha) S \\
& \frac{d V}{d t}=p \Lambda+\alpha S-\beta_{1} V I-\left(\mu+\gamma_{1}\right) V \\
& \frac{d I}{d t}=\beta S I+\beta_{1} V I-(\gamma+\mu+\omega) I
\end{aligned}
$$




$$
\frac{d R}{d t}=\gamma_{1} V+\gamma I-\mu R
$$

dengan kondisi awal $S(0)=S_{0} \geq 0, V(0)=V_{0} \geq 0, I(0)=I_{0} \geq 0$ dan $R(0)=R_{0} \geq 0$. Semua parameter dalam Persamaan (1)-(4) bernilai positif. Deskripsi parameter-parameter tersebut disajikan dalam Tabel 1, berikut:

Tabel 1. Deskripsi parameter-parameter dalam model SVIR

\begin{tabular}{|cl|}
\hline Parameter & \multicolumn{1}{c|}{ Deskripsi } \\
\hline$\Lambda$ & Laju rekruitmen \\
$\mu$ & Laju kematian alami \\
$\beta$ & Laju transmisi (laju kontak) individu yang terinfeksi terhadap individu \\
$\beta_{1}$ & rentan \\
$\gamma$ & Laju transmisi individu yang divaksin terhadap individu terinfeksi \\
& Laju rata-rata pemulihan individu terinfeksi karena pengobatan dan \\
$\gamma_{1}$ & kekebalan alami. \\
$\alpha$ & Laju rata-rata individu yang divaksin menjadi kebal terhadap penyakit \\
$\omega$ & Laju rata-rata individu rentan yang diberikan vaksin \\
$p$ & Laju kematian karena penyakit \\
& $\begin{array}{l}\text { Proporsi jumlah individu divaksin yang masuk dalam kompartemen } \mathrm{V} \\
\end{array}$ \\
\end{tabular}

Teorema 1. Saat $t \rightarrow \infty$, semua solusi Sistem Persamaan (1)-(4) berada pada

$$
\Omega=\left\{(S, V, I, R) \in R_{4}^{+}: N \leq \frac{\Lambda}{\mu}\right\}, \forall\left(S_{0}, V_{0}, I_{0}, R_{0}\right) \in R_{4}^{+} .
$$

Bukti. Misalkan ruas kanan Sistem Persamaan (1)-(4) ditulis sebagai

$$
f(S, V, I, R)=\left(\begin{array}{c}
(1-p) \mu-\beta S I-(\mu+\alpha) S \\
p \mu+\alpha S-\beta_{1} V I-\left(\mu+\gamma_{1}\right) V \\
\beta S I+\beta_{1} V I-(\gamma+\mu+\omega) I \\
\gamma_{1} V+\gamma I-\mu R
\end{array}\right)
$$

Karena $f$ tersebut diferensiabel kontinu di $R_{4}^{+}$, maka menurut teorema eksistensi dan ketunggalan solusi sistem persamaan diferensial [13], Sistem Persamaan (1)-(4) memiliki solusi tunggal. Jika Persamaan (1)-(4) dijumlahkan, maka diperoleh:

Sehingga berlaku

$$
\frac{d N}{d t}=\Lambda-\mu N-\omega I \leq \Lambda-\mu N
$$

Akibatnya, saat $t \rightarrow \infty$ diperoleh

$$
N(t) \leq N_{0} e^{-\mu t}+\frac{\Lambda}{\mu}\left(1-e^{-\mu t}\right)
$$

$$
N(t) \leq \frac{\Lambda}{\mu}, \forall\left(S_{0}, V_{0}, I_{0}, R_{0}\right) \in R_{4}^{+}
$$

\subsection{Eksistensi Titik Ekuilibrium dan Bilangan Reproduksi Dasar}

Titik ekuilibrium Sistem Persamaan (1)-(4) diperoleh dengan menyelesaikan persamaan

$$
\frac{d S}{d t}=\frac{d V}{d t}=\frac{d I}{d t}=\frac{d R}{d t}=0
$$

Sehingga dari Sistem Persamaan (1)-(4), diperoleh

$$
\begin{aligned}
(1-p) \Lambda-\beta S I-(\mu+\alpha) S & =0 \\
p \Lambda+\alpha S-\beta_{1} V I-\left(\mu+\gamma_{1}\right) V & =0 \\
\beta S I+\beta_{1} V I-(\gamma+\mu+\omega) I & =0 \\
\gamma_{1} V+\gamma I-\mu R & =0
\end{aligned}
$$

Dari Persamaan (7), diperoleh

$$
I\left(\beta S+\beta_{1} V-\gamma-\mu-\omega\right)=0
$$

dengan demikian, didapatkan dua kasus untuk menyelesaikan Sistem Persamaan (5)-(8), yaitu kasus $I=0$ dan kasus $I \neq 0$ yang berarti bahwa $\beta S+\beta_{1} V-\gamma-\mu-\omega=0$. Untuk kasus $I=0$, dinotasikan $S=S^{0}$, $V=V^{0}, I=I^{0}$ dan $R=R^{0}$. Jika $I^{0}=0$, maka dari Sistem Persamaan (5)-(8) diperoleh 


$$
\begin{gathered}
S^{0}=\frac{(1-p) \Lambda}{\mu+\alpha} \\
V^{0}=\frac{p \Lambda(\mu+\alpha)+\alpha \Lambda(1-p)}{\left(\mu+\gamma_{1}\right)(\mu+\alpha)} \\
I^{0}=0 \\
R^{0}=\frac{\gamma_{1} p \Lambda(\mu+\alpha)+\gamma_{1} \alpha \Lambda(1-p)}{\mu\left(\mu+\gamma_{1}\right)(\mu+\alpha)}
\end{gathered}
$$

Jadi, diperoleh satu titik ekuilibrium $E^{0}=\left(S^{0}, V^{0}, 0, R^{0}\right)$ yang disebut titik ekuilibrium bebas penyakit. Untuk kasus $I \neq 0$, dari Persamaan (7) diperoleh bahwa

$$
\beta S+\beta_{1} V-\gamma-\mu-\omega=0
$$

Untuk kasus ini, dinotasikan $S=S^{*}, V=V^{*}, I=I^{*}$ dan $R=R^{*}$. Dari Persamaan (5), diperoleh

Dari Persamaan (6), diperoleh

$$
S^{*}=\frac{(1-p) \Lambda}{\beta I^{*}+\mu+\alpha}
$$

Dari Persamaan (8), diperoleh

$$
V^{*}=\frac{p \Lambda+\alpha S^{*}}{\beta_{1} I^{*}+\mu+\gamma_{1}}
$$

$$
R^{*}=\frac{\gamma_{1} V+\gamma I^{*}}{\mu}
$$

Jika $S^{*}$ dan $V^{*}$ disubtitusikan ke Persamaan (9), maka diperoleh persamaan kuadrat berikut:

dengan

$$
A_{1} I^{* 2}+A_{2} I^{*}+A_{3}(1-k)=0
$$

$A_{1}=(\gamma+\mu+\omega) \beta \beta_{1}>0$

$A_{2}=(\gamma+\mu+\omega)\left((\alpha+\mu) \beta_{1}+\beta\left(\gamma_{1}+\mu\right)\right)-\left(\beta \Lambda(1-p)+\beta_{1} p \Lambda\right)$

$A_{3}=(\gamma+\mu+\omega)(\alpha+\mu)\left(\gamma_{1}+\mu\right)>0$

$k=\frac{\beta \Lambda(1-p)\left(\gamma_{1}+\mu\right)+\beta_{1} p \Lambda(\mu+\alpha)+\beta_{1} \alpha \Lambda(1-p)}{(\gamma+\mu+\omega)(\mu+\alpha)\left(\mu+\gamma_{1}\right)}$

$I^{*}$ merupakan akar positif dari Persamaan kuadrat (10), yaitu:

$$
I_{1,2}{ }^{*}=\frac{-A_{2} \pm \sqrt{A_{2}{ }^{2}-4 A_{1} A_{3}(1-k)}}{2 A_{1}}
$$

Untuk kasus $I \neq 0$, diperoleh titik ekuilibrium $E^{*}=\left(S^{*}, V^{*}, I^{*}, R^{*}\right)$ dengan $I^{*}$ merupakan akar positif. Persamaan (10). Titik ekuilibrium $E^{*}$ disebut sebagai titik ekuilibrium endemik. Eksistensi $I^{*}$ bernilai positif bergantung pada nilai $k$. Oleh karena itu, $k$ dijadikan sebagai tolak ukur eksistensi titik ekuilibrium Sistem (1)-(4) untuk kasus $I \neq 0$. Akibatnya, $k$ dapat didefinisikan sebagai bilangan reproduksi dasar

$$
R_{0}=\frac{\beta \Lambda(1-p)\left(\gamma_{1}+\mu\right)+\beta_{1} p \Lambda(\mu+\alpha)+\beta_{1} \alpha \Lambda(1-p)}{(\gamma+\mu+\omega)(\mu+\alpha)\left(\mu+\gamma_{1}\right)}
$$

Selanjutnya, pembahasan secara keseluruhan terkait eksistensi titik ekuilibrium Sistem (1)-(4) yang melibatkan $R_{0}$ di atas dapat dituliskan secara singkat dalam teorema berikut.

Teorema 2. Jika $R_{0} \leq 1$, maka Sistem (1)-(4) memiliki satu titik ekuilibrium yang disebut sebagai titik ekuilibrium bebas penyakit $E^{0}=\left(S^{0}, V^{0}, 0, R^{0}\right)$. Sebaliknya, jika $R_{0}>1$, maka Sistem (1)-(4) memiliki dua titik ekuilibrium, yaitu titik ekuilbrium bebas penyakit $E^{0}=\left(S^{0}, V^{0}, 0, R^{0}\right)$ dan titik ekuilibrium endemik $E^{*}=\left(S^{*}, V^{*}, I^{*}, R^{*}\right)$ dengan $R_{0}$ diberikan pada Persamaan (11).

\subsection{Kestabilan Lokal Titik Ekuilibrium}

Pembahasan berikut ini terkait analisis kestabilan lokal titik ekuilbrium Sistem (1)-(4). Matriks Jacobian dari Sistem (1)-(4) digunakan untuk menentukan kestabilan lokal titik ekuilibrium sistem tersebut. Kestabilan lokal titik ekuilibrium sistem tersebut diberikan dalam teorema berikut.

Teorema 3. Jika $R_{0}<1$, maka $E^{0}$ stabil asimtotik lokal. Sebaliknya, jika $R_{0}>1$, maka $E^{0}$ tidak stabil, tetapi $E^{*}$ stabil asimtotik lokal. 
Bukti. Diperhatikan bahwa Persamaan (4) tidak akan berpengaruh terhadap Persamaan (1)-(3) karena pada Persamaan (1)-(3) tidak memuat $R$ sehingga sistem yang dibahas akan difokuskan pada Persamaan (1)-(3). Berdasarkan [13], matriks Jacobian Sistem (1)-(3) di titik $E^{0}$, yaitu:

$$
J\left(E^{0}\right)=\left[\begin{array}{ccc}
-(\mu+\alpha) & 0 & -\beta S^{0} \\
\alpha & -\left(\mu+\gamma_{1}\right) & -\beta_{1} V^{0} \\
0 & 0 & m
\end{array}\right]
$$

dengan $m=\beta S^{0}+\beta_{1} V^{0}-\gamma-\mu-\omega$.

Persamaan karakteristik matriks $J\left(E^{0}\right)$, yaitu $(\lambda+\alpha+\mu)\left(\lambda+\mu+\gamma_{1}\right)(\lambda-m)=0$, sehingga diperoleh nilai eigen matriks $J\left(E^{0}\right)$ adalah $\lambda_{1}=-(\mu+\alpha), \quad \lambda_{2}=-\left(\mu+\gamma_{1}\right)$ dan $\lambda_{3}=(\gamma+\mu+\omega)\left(R_{0}-1\right)$. Jika diperhatikan nilai eigen $\lambda_{1}$ dan $\lambda_{2}$, jelas bahwa dua nilai eigen tersebut bernilai negatif, sedangkan $\lambda_{3}$ akan bernilai negatif tergantung pada nilai $R_{0}$. Berdasarkan [14], jika seluruh nilai eigen matriks Jacobian $J\left(E^{0}\right)$ bernilai negatif, maka $E^{0}$ stabil asimtotik lokal. Oleh karena itu, jika $R_{0}<1$, maka $E^{0}$ stabil asismtotik lokal. Sebaliknya, jika $R_{0}>1$, maka $E^{0}$ tidak stabil karena $\lambda_{3}$ bernilai positif. Matriks Jacobian Sistem (1)-(3) di titik $E^{*}$, yaitu:

$$
J\left(E^{*}\right)=\left[\begin{array}{ccc}
-\left(\mu+\alpha+\beta I^{*}\right) & 0 & -\beta S^{*} \\
\alpha & -\left(\mu+\gamma_{1}+\beta_{1} I^{*}\right) & -\beta_{1} V^{*} \\
\beta I^{*} & \beta_{1} I^{*} & r
\end{array}\right]
$$

dengan $r=\beta S^{*}+\beta_{1} V^{*}-\gamma-\mu-\omega$.

Diketahui bahwa

$$
\begin{gathered}
\mu+\alpha+\beta I^{*}=\frac{(1-p) \Lambda}{S^{*}} \\
\mu+\gamma_{1}+\beta_{1} I^{*}=\frac{p \Lambda+\alpha S^{*}}{V^{*}} \\
r=\beta S^{*}+\beta_{1} V^{*}-\gamma-\mu-\omega=0
\end{gathered}
$$

Akibatnya,

$$
J\left(E^{*}\right)=\left[\begin{array}{ccc}
-\frac{(1-p) \Lambda}{S^{*}} & 0 & -\beta S^{*} \\
\alpha & -\frac{p \Lambda+\alpha S^{*}}{V^{*}} & -\beta_{1} V^{*} \\
\beta I^{*} & \beta_{1} I^{*} & 0
\end{array}\right]
$$

Persamaan karakteristik matriks Jacobian $J\left(E^{*}\right)$, yaitu:

dengan

$$
\lambda^{3}+a_{1} \lambda^{2}+a_{2} \lambda+a_{3}=0
$$

$a_{1}=a+b$

$a_{2}=a b+\beta_{1}^{2} V^{*} I^{*}+\beta^{2} S^{*} I^{*}$

$a_{3}=\alpha \beta_{1} \beta S^{*} I^{*}+a \beta_{1}^{2} V^{*} I^{*}+b \beta^{2} S^{* 2} I^{*}$

$a=\frac{(1-p) \Lambda}{S^{*}}$

$b=\frac{p \Lambda+\alpha S^{*}}{V^{*}}$

Sehingga diperoleh

$$
\begin{aligned}
a_{1} a_{2}-a_{3} & =(a+b)\left(a b+\beta_{1}{ }^{2} V^{*} I^{*}+\beta^{2} S^{*} I^{*}\right)-\alpha \beta_{1} \beta S^{*} I^{*}-a \beta_{1}{ }^{2} V^{*} I^{*}-b \beta^{2} S^{* 2} I^{*} \\
& =a^{2} b+a b^{2}+a \beta^{2} S^{*} I^{*}+b \beta_{1}{ }^{2} V^{*} I^{*}-\alpha \beta_{1} \beta S^{*} I^{*}
\end{aligned}
$$

Diperhatikan bahwa

$$
a \beta_{1}{ }^{2} S^{*} I^{*}=\left(\mu+\alpha+\beta I^{*}\right) \beta_{1}{ }^{2} S^{*} I^{*}
$$

dan

Sehingga

$$
b \beta_{1}{ }^{2} V^{*} I^{*}-\alpha \beta_{1} \beta S^{*} I^{*}=p \Lambda \beta_{1}{ }^{2} I^{*}+\alpha \beta_{1}{ }^{2} S^{*} I^{*}-\alpha \beta_{1} \beta S^{*} I^{*}
$$

Akibatnya,

$$
a_{1} a_{2}-a_{3}=a^{2} b+a b^{2}+\left(\mu+\alpha+\beta I^{*}\right) \beta^{2} S^{*} I^{*}+p \Lambda \beta_{1}{ }^{2} I^{*}+\alpha \beta_{1}{ }^{2} S^{*} I^{*}-\alpha \beta_{1} \beta S^{*} I^{*}
$$

$$
a_{1} a_{2}-a_{3}=a^{2} b+a b^{2}+\left(\mu+\beta I^{*}\right) \beta^{2} S^{*} I^{*}+p \Lambda \beta_{1}{ }^{2} I^{*}+\alpha\left(\beta-\beta_{1}\right)^{2} S^{*} I^{*}+\alpha \beta_{1} \beta S^{*} I^{*}>0
$$


dapat diperhatikan bahwa semua koefisien $a_{1}, a_{2}$ dan $a_{3}$ bernilai positif dan $a_{1} a_{2}-a_{3}$ juga bernilai positif. Oleh karena itu, berdasarkan kriteria Routh-Hurwitz, seluruh bagian real dari nilai eigen Persamaan (12) bernilai negatif. Dengan demikian, titik ekuilibrium $E^{*}$ stabil asimtotik lokal. Jadi, jika $R_{0}>1$, maka terdapat $E^{*}$ yang stabil asimtotik lokal.

Bilangan reproduksi dasar yang diperoleh memuat proporsi dari jumlah individu yang masuk pada kompartemen $V$. Proporsi tersebut dinotasikan sebagai parameter $p$. Hal ini berarti bahwa parameter $p$ memberikan pengaruh pada nilai bilangan reproduksi dasar. Semakin besar nilai parameter $p$ akan mengakibatkan semakin kecil nilai bilangan reproduksi dasar. Interpretasi secara biologis terkait kestabilan titik ekuilibrium Sistem Persamaan (1)-(4) adalah jika bilangan reproduksi dasar yang telah diperoleh dari model nilainya kurang dari satu, maka dalam jangka waktu yang terus berjalan, jumlah populasi $S$ cenderung menuju nilai $S^{0}$, jumlah populasi $V$ cenderung menuju nilai $V^{0}$, jumlah populasi $I$ cenderung turun menuju 0 dan jumlah populasi $R$ cenderung menuju nilai $R^{0}$. Hal ini berarti bahwa penyakit dalam populasi cenderung turun dalam waktu yang terus berjalan sampai waktu yang tak terhingga. Dengan kata lain, penyakit tidak akan mewabah sepanjang waktu. Jika bilangan reproduksi dasar yang telah diperoleh dari model nilainya lebih dari satu, maka dalam jangka waktu yang terus berjalan, jumlah populasi $S$ cenderung menuju nilai $S^{*}$, jumlah populasi $V$ cenderung menuju nilai $V^{*}$, jumlah populasi $I$ cenderung naik menuju $I^{*}$ dan jumlah populasi $R$ cenderung menuju nilai $R^{*}$. Hal ini berarti bahwa penyakit akan tetap berada dalam populasi dengan jumlah populasi terinfeksi cenderung menuju nilai $I^{*}$ dalam waktu yang terus berjalan sampai waktu yang tak terhingga. Dengan kata lain, penyakit masih akan terus mewabah di dalam populasi sampai waktu yang tak terhingga.

\section{KESIMPULAN}

Dari pembahasan dapat disimpulkan bahwa eksistensi titik ekuilibrium model SVIR dan kestabilannya bergantung pada nilai bilangan reproduksi dasar. Jika bilangan reproduksi dasar kurang dari satu maka terdapat dengan tunggal titik ekuilibrium bebas penyakit dan titik ekuilibrium tersebut stabil asimtotik lokal. Hal ini berarti bahwa jika kondisi bilangan reproduksi dasar bernilai kurang dari satu maka penyakit akan cenderung menghilang dalam populasi. Sebaliknya, jika bilangan reproduksi dasar lebih dari satu, maka terdapat dua titik ekuilibrium, yaitu titik ekuilibrium bebas penyakit dan titik ekuilibrium endemik. Dalam kondisi ini, titik ekuilibrium endemik stabil asimtotik lokal. Hal ini berarti bahwa jika nilai dari bilangan reproduksi dasar lebih dari satu, maka penyakit akan tetap ada dalam populasi. Dinamika lokal epidemi SVIR yang terjadi dalam suatu populasi dapat dideskripsikan melalui bilangan reproduksi dasar yang bergantung pada parameter-parameter dalam model.

\section{DAFTAR PUSTAKA}

[1] W. O. Kermack and A. G. McKendrick, "Contributions to the mathematical theory of epidemics-I," Bull. Math. Biol., 1991.

[2] C. M. Kribs-Zaleta and J. X. Velasco-Hernández, "A simple vaccination model with multiple endemic states," Math. Biosci., 2000.

[3] M. E. Alexander, C. Bowman, S. M. Moghadas, R. Summers, A. B. Gumel, and B. M. Sahai, "A vaccination model for transmission dynamics of influenza," SIAM J. Appl. Dyn. Syst., 2004.

[4] E. Shim, "A note on epidemic models with infective immigrants and vaccination," Mathematical Biosciences and Engineering. 2006.

[5] A. d'Onofrio, P. Manfredi, and E. Salinelli, "Vaccinating behaviour, information, and the dynamics of SIR vaccine preventable diseases," Theor. Popul. Biol., 2007.

[6] X. Liu, Y. Takeuchi, and S. Iwami, "SVIR epidemic models with vaccination strategies," J. Theor. Biol., 2008.

[7] S. Henshaw and C. Connell McCluskey, "Global stability of a vaccination model with immigration," Electron. J. Differ. Equations, vol. 2015, no. 92, pp. 1-10, 2015.

[8] S. Islam, "Equilibriums and Stability of an SVIR Epidemic Model," BEST Int. J. Humanit. Arts, Med. Sci. (BEST IJHAMS) , 2015.

[9] M. A. Khan et al., "Stability analysis of an SVIR epidemic model with non-linear saturated incidence rate," Appl. Math. Sci., 2015.

[10] J. Harianto, "Local Stability Analysis of an SVIR Epidemic Model," CAUCHY, 2017.

[11] J. Harianto and T. Suparwati, "SVIR Epidemic Model with Non Constant Population," CAUCHY, 2018. 
[12] A. Ibra and W. Purnami, "Model Susceptible Vaccinated Infected Recovered (SVIR) dan Penerapannya pada Penyakit Difteri di Indonesia," in PRISMA, 2020, pp. 156-162.

[13] L. Perko, Differential Equations and Dynamical Systems, 3th ed. New York: Springer, 2001.

[14] G. J. Olsder, Mathematical System Theory, vi. Netherland: Delftse Uitgevers Maatschappij, 1994. 